Economics Development Analysis Journal 7 (2)(2018)

\title{
Analisis Faktor Penentu Keputusan Tinggal Masyarakat Kelurahan Karangroto di Rusunawa
}

\author{
Akhmad Anggi Asfani ${ }^{1 凶}$, Karsinah $^{2}$
}

Jurusan Ekonomi Pembangunan, Fakultas Ekonomi, Universitas Negeri Semarang

\begin{tabular}{l} 
Info Artikel \\
\hline Sejarah Artikel: \\
Diterima Januari 2018 \\
Disetujui Maret 2018 \\
Dipublikasikan Mei 2018
\end{tabular}

Keywords:

Vertical Housing, Backlog,

Environment, Chance,

Logistic Binary Regression.

\begin{abstract}
Abstrak
Rusunawa adalah program dari pemerintah untuk mengurangi jumlah angka kekurangan rumah (backlog). Tujuan dari penelitian ini adalah menganalisis besar peluang faktor harga sewa, pendapatan keluarga, jumlah anggota keluarga, kualitas bangunan, lingkungan rusunawa, dan jarak tempat kerja terhadap keputusan tinggal masyarakat Kelurahan Karangroto di Rusunawa. Penelitian ini berlokasi di Kelurahan Karangroto, Kecamatan Genuk, Kota Semarang. Penelitian ini menggunakan metode teknik acak proporsional yang mengambil dari 1360 populasi diambil sejumlah 99 responden untuk diteliti. Metode analisis yang digunakan adalah analisis deskriptif kualitatif dan deskriptif kuantitatif menggunakan alat analisis regresi binary logistik. Kesimpulan dari penelitian ini adalah faktor-faktor yang mempengaruhi keputusan tinggal masyarakat Karangroto yaitu pendapatan keluarga, kualitas bangunan, lingkungan rusunawa dan jarak tempat kerja. Besarnya probabilitas dari masing-masing faktor yang berpengaruh adalah faktor pendapatan keluarga dengan nilai odds rasio sebesar 0,765 . Faktor kualitas bangunan dengan nilai probabilitas odds rasio sebesar 79,810. Faktor lingkungan rusunawa dengan nilai probabilitas odds rasio sebesar 23,035. Faktor jarak tempat kerja dengan nilai probabilitas odds rasio sebesar 1,242.
\end{abstract}

\begin{abstract}
Low-income housing is a government program for decreasing the number of housing shortages (backlog). The goal of this research is for analyzing how many the factors of rental costs, family income, and family member, building quality, the environment and the distance of workplace influence the decision of people in Karangroto to stay in low-income housing. This research was done in Karangroto village, Genuk district, and Semarang city. The method of proportional random technique was used in this research which took 99 respondents of 1360 population. Analyzing method which was used is qualitative descriptive analysis and quantitative descriptive by using logistic binary regression tools. The conclusion of this research is that the factors which influence people of Karangroto to stay in low-income housing are family income, building quality, its environment, and the distance of workplace. The probability magnitude of each factor which mostly influenced is family income by the ratio odds 0,765. Factors of building quality have probability of odds ratio 79.810. Environment factors of low-income housing have the probability of odds ratio 23.035. Then, factors of the distance of workplace have its probability odds ratio 1.242 .
\end{abstract}




\section{PENDAHULUAN}

Kelurahan Karangroto merupakan daerah yang berada di Kecamatan Genuk, Kota Semarang yang dekat dengan perbatasan Kabupaten Demak. Kelurahan Karangroto memiliki masyarakat yang terdiri dari 3.299 Kepala Keluarga dengan jumlah hunian (Rumah) sebanyak 2.301 unit rumah. Jumlah angka Backlog di Kelurahan Karangroto sebanyak 988. Rusunawa Karangroto telah dibangun pada tahun 2012 dengan jumlah 4 twin blok berkapasitas 384 unit hunian, seharusnya Rusunawa Karangroto mampu mengurangi jumlah kekurangan rumah yang berada di Kelurahan Karangroto sendiri, akan tetapi sejumlah 372 unit hunian yang dihuni hanya dihuni sebanyak 38 kepala keluarga masyarakat yang berasal dari Kelurahan Karangroto atau hanya $10 \%$ saja.

Rusunawa Karangroto menawarkan sebuah harga sewa yang ringan bagi masyarakat, harga sewa yang ringan diharapkan mampu menarik minat masyarakat untuk menghuni sebuah bangunan vertikal yang disediakan oleh pemerintah ini. Seperti pada penelitian yang dilakukan oleh Dahmiri (2010) bahwa harga sangat mempengaruhi konsumen dalam mengambil keputusan membeli rumah, terlihat dari nilai indeksnya yang merupakan variabel dengan nilai indeks tertinggi yaitu sebesar 54,8 . Pada penelitian yang dilakukan oleh Dahmiri merupakan penelitian dengan studi kasus perumahan komersial, sedangan penelitian ini memilih studi kasus yang merupakan hunian tidak komersial, sehingga harga sewa dimasukkan pada faktor yang diteliti.

Data wawancara yang dilakukan berkaitan dengan pendapatan, bahwa pendapatan masyarakat akan lebih diutamakan untuk disimpan dan digunakan untuk membangun sebuah hunian sendiri. Penelitian yang dilakukan oleh Hutomo (2015) variabel pendapatan berpengaruh secara signifikan terhadap keputusan tenaga kerja melakukan migrasi ulang-alik. Mulyo Budi S (2009) mengemukakan bahwa pendapatan sangat berpengaruh terhadap perubahan kebutuhan rumah yang menunjukkan bahwa kenaikan pendapatan konsumen sebesar $1 \%$ akan berdampak pada peningkatan kebutuhan rumah sebesar $1,3 \%$, atau bila pendapatan menurun $1 \%$ akan menurunkan permintaan rumah $1,3 \%$, untuk terjadinya kondisi tersebut bila variabel lainnya diasumsikan tetap, sehingga faktor pendapatan akan dimasukkan pada faktor yang diteliti.

Faktor keluarga seperti yang dikemukakan pada wawancara bersinggungan dengan jumlah anggota keluarga. Pada penelitian yang dilakukan oleh Sumarmi (2011) yang mengemukakan bahwa faktor eksternal input diantaranya adalah faktor kebudayaan, faktor sosial, faktor referensi dan faktor keluarga secara parsial terbukti secara positif dan signifikan terhadap keputusan pemilihan perumahan, sehingga jumlah anggota keluarga di masukkan pada penelitian ini.

Penelitian yang dilakukan oleh Dahmiri (2011) mengemukakan bahwa meskipun kualitas rumah bukan merupakan faktor atau indikator yang paling utama oleh masyarakat dalam keputusaan konsumen membeli rumah, akan tetapi kualitas rumah juga berpengaruh signifikan terhadap keputusan konsumen membeli rumah. Data wawancara juga ada yang berkaaitan mengenai kualitas bangunan rusunawa, maka kualitas bangunan dijadikan faktor yang diteliti pada penelitian ini.

Faktor lingkugan juga ada kaitan antara penelitian yang sudah diteliti oleh Annisa Purbosari (2012) yang mengemukakan bahwa faktor lingkungan mempunyai pengaruh secara parsial sebesar 0,033 terhadap keputusan bertempat tinggal di kota Bekasi dengan wawancara yang dilakukan bahwa masyarakat mengemukakan lingkungan tempat tinggal saat ini lebih nyaman. Faktor lingkungan dimasukkan sebagai faktor yang diteliti pada penelitian ini.

Wawancara yang dilakukan pada awal observasi juga menemukan bahwa adanya masyarakat yang enggan memilih Rusunawa sebagai hunian alternative karena faktor tempat kerjanya. Penelitian yang dilakukan oleh Kalesaran (2013) mengemukakan bahwa 
variabel "Dekat dengan tempat kerja/usaha" memiliki loading factor 0,517 pada komponen 1, loading factor $-0,344$ pada komponen 10 , sehingga dimasukkan dalam komponen 1 dan masuk pada loading factor yang mempengaruhi pemilihan perumahan oleh konsumen. Faktor jarak tempat kerja dimasukkan pada peneitian ini.

Mengacu pada Peraturan Walikota Semarang yang menyebutkan bahwa calon penghuni merupakan masyarakat yang berdomisili di wilayah daerah, sehingga penelitian ini fokus pada faktor-faktor yang berpengaruh terhadap keputusan tinggal masyarakat Karangroto di Rusunawa dan probabilitas keputusan tinggal masyarakat Karangroto di Rusunawa.

\section{METODE PENELITIAN}

Penelitian ini merupakan penelitian yang menggunakan analisis secara deskriptif kualitatif dan deskriptif kuantitatif. Hasil pengumpulan data primer ditabulasi sesuai dengan kelompok data masing-masing. Pengukuran tingkat persepsi masyarakat dilihat dari variabel independen, yaitu : harga sewa, pendapatan keluarga, jumlah anggota keluarga, kualitas bangunan, lingkungan rusunawa, dan jarak tempat kerja.

Penelitian ini menggunakan variabel harga sewa, pendapatan keluarga, jumlah anggota keluarga, kualitas bangunan, lingkungan rusunawa, dan jarak tempat kerja sebagai variabel independen. Variabel dependen dalam penelitian ini adalah Keputusan tinggal masyarakat Karangroto di Rusunawa.

Penelitian ini menggunakan metode pengumpulan data dengan cara wawancara, kuesioner, dan dokumentasi. Wawancara merupakan alat yang digunakan untuk menggali lebih mengenai informasi mengenai Rusunawa Karangroto, kuesioner merupakan alat yang digunakan untuk mencari data kuantitatif sebagai data untuk pengolahan data, dokumentasi merupakan alat yang digunakan untuk menggali data sebagai penunjang

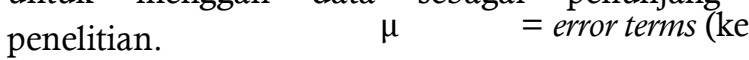

Penelitian ini menggunakan metode penelitian kuantitatif dengan menggunakan data primer. Menurut Supranto (2000) data primer adalah data yang dikumpulkan dan diolah sendiri langsung dari obyeknya. Untuk mengetahui besar pengaruh variabel independen terhadap variabel dependen akan dianalisis menggunakan model Regresi logistik yang digunakan untuk menguji apakah probabilitas terjadinya variabel dependen dapat diprediksi dengan variabel independen. Pada teknik analisis regresi logistik tidak memerlukan lagi uji normalitas dan uji asumsi klasik pada variabel bebasnya (Ghozali, 2011). Model logit dengan dua pilihan sering disebut sebagai binary logistic regression. Alat yang digunakan untuk mempermudah pengolahan data pada penelitian ini adalah software SPSS.

Analisis data yang digunakan untuk mengetahui faktor-faktor yang mempengaruhi keputusan masyarakat untuk memilih tinggal di rusunawa dilakukan dengan menggunakan analisis regresi logit. Bentuk persamaan regresi logit adalah sebagai berikut :
DECISION $=\ln (\quad) \beta 0+\beta 1$ XRENT $+\beta 2$
XINCOME $+\beta 3$ FAMILY $+\beta 4$ QUALITY $+\beta 5$
XENVIRONTMENT $+\beta 6 D I S T A N C E+\mu$

Dimana:

DECISION

$$
\begin{aligned}
= & \text { keputusan tinggal di } \\
& \text { Rusunawa } \\
& \text { Karangroto, } 1 \text { jika } \\
& \text { responden tinggal di } \\
& \text { rusunawa dan } 0 \text { jika } \\
& \text { lainnya. } \\
= & \text { harga sewa } \\
= & \text { pendapatan keluarga } \\
= & \text { jumlah anggota } \\
& \text { keluarga } \\
= & \text { kualitas bangunan } \\
= & \text { lingkungan } \\
& \text { rusunawa }
\end{aligned}
$$$$
\text { RENT = harga sewa }
$$$$
\text { INCOME = pendapatan keluarga }
$$$$
\text { FAMILY = jumlah anggota }
$$$$
\text { QUALITY = kualitas bangunan }
$$$$
\text { ENVIRONTMENT = lingkungan }
$$$$
\text { DISTANCE = jarak tempat kerja }
$$$$
\text { ln } \quad \text { logaritma natural }
$$$$
\mathrm{p}=\text { probabilitas }
$$$$
\beta \quad=\text { koefisien regresi }
$$ 


\section{HASIL DAN PEMBAHASAN}

$$
\frac{p}{1-\boldsymbol{p}} \text { Model regresi binary logistik }
$$

terkait pengaruh harga sewa, pendapatan keluaarga, jumlah anggota keluarga, kualitas bangunan, lingkungan rusunawa dan jarak tempat kerja terhadap keputusan tinggal masyarakat Karangroto di rusunawa. Persamaan model regresi binary logistik sebagai berikut :

$$
\begin{aligned}
\text { DECISION }= & \ln (\quad)-9,884- \\
& 0,268 X R E N T+ \\
& 2,709 \text { XINCOME }- \\
& 0,832 X F A M I L Y+ \\
& 4,380 X Q U A L I T Y+ \\
& 3,137 \text { XENVIRONTMENT }+ \\
& 0,217 \text { XDISTANCE }+\mu
\end{aligned}
$$

Tabel 1. Variables in the Equation

\begin{tabular}{lllllllll}
\hline Variabel & & & & & & \multicolumn{2}{c}{$95,0 \%$} & C.I for EXP \\
& B & S.E. & Wald & Df & Sig. & $\begin{array}{l}\text { Exp }(B) \\
(B) \\
\text { Lower }\end{array}$ & Upper \\
\hline Harga sewa & -.268 & 1.368 & .038 & 1 & .845 & .765 & .052 & 11.167 \\
Pendapatan keluarga & 2.709 & 1.243 & 4.752 & 1 & .029 & 15.017 & 1.314 & 171.589 \\
JAK & -.832 & .640 & 1.693 & 1 & .193 & .435 & .124 & 1.524 \\
Kualitas bangunan & 4.380 & 1.636 & 7.168 & 1 & .007 & 79.810 & 3.233 & 1.970 \\
Lingkungan rusunawa & 3.137 & 1.177 & 7.099 & 1 & .008 & 23.035 & 2.292 & 231.521 \\
Jarak tempat kerja & & & & & & & & \\
Constant & .217 & .084 & 6.654 & 1 & .010 & 1.242 & 1.054 & 1.465 \\
\hline
\end{tabular}

Sumber : Data Primer (diolah)

Koefisien variabel harga sewa diperoleh sebesar -0,268 pada estimasi binary logistic regression memiliki tingkat signifikan sebesar 0,845 . Tingkat signifikan tersebut mempunyai nilai signifikan $>$ taraf nyata $(\alpha=0,05)$. Variabel harga sewa dapat diartikan bahwa variabel harga sewa tidak berpengaruh signifikan negatif terhadap keputusan tinggal masyarakat Karangroto di Rusunawa. Koefisien variabel pendapatan keluarga diperoleh sebesar 2,709 pada estimasi binary logistic regression memiliki tingkat signifikan sebesar 0,029. Tingkat signifikan tersebut mempunyai nilai signifikan < taraf nyata $(\alpha=0,05)$. Variabel pendapatan keluarga dapat diartikan bahwa variabel pendapatan keluarga berpengaruh signifikan positif terhadap keputusan tinggal masyarakat Karangroto di Rusunawa. Koefisien variabel jumlah anggota keluarga diperoleh sebesar $-0,832$ pada estimasi binary logistic regression memiliki tingkat signifikan sebesar 0,193. Tingkat signifikan tersebut mempunyai nilai signifikan $>$ taraf nyata $(\alpha=0,05)$. Variabel jumlah anggota keluarga dapat diartikan bahwa variabel jumlah anggota keluarga tidak berpengaruh signifikan negatif terhadap keputusan tinggal masyarakat Karangroto di Rusunawa.

Koefisien variabel kualitas bangunan diperoleh sebesar 4,380 pada estimasi binary logistic regression memiliki tingkat signifikan sebesar 0,007. Tingkat signifikan tersebut mempunyai nilai signifikan $<$ taraf nyata $(\alpha=$ $0,05)$. Variabel harga sewa dapat diartikan bahwa variabel kualitas bangunan berpengaruh signifikan positif terhadap keputusan tinggal masyarakat Karangroto di Rusunawa.

Koefisien variabel lingkungan rusunawa diperoleh sebesar 3,137 pada estimasi binary 
logistic regression memiliki tingkat signifikan sebesar 0,008. Tingkat signifikan tersebut mempunyai nilai signifikan $<$ taraf nyata $(\alpha=$ $0,05)$. Variabel lingkungan rusunawa dapat diartikan bahwa variabel lingkungan rusunawa berpengaruh signifikan positif terhadap keputusan tinggal masyarakat Karangroto di Rusunawa.

Koefisien variabel jarak tempat kerja diperoleh sebesar 0,217 pada estimasi binary logistic regression memiliki tingkat signifikan sebesar 0,010. Tingkat signifikan tersebut mempunyai nilai signifikan $<$ taraf nyata $(\alpha=$ $0,05)$. Variabel jarak tempat kerja dapat diartikan bahwa variabel jarak tempat kerja berpengaruh signifikan positif terhadap keputusan tinggal masyarakat Karangroto di Rusunawa.

Pengaruh Harga Sewa Terhadap Permintaan Rusunawa Sebagai Tempat Tinggal Masyarakat Kelurahan Karangroto, variabel harga sewa dengan nilai signifikansi 0,845 , dimana nilai signifikansi lebih dari nilai $p$-value 0,05 maka variabel harga sewa tidak berpengaruh signifikan terhadap permintaan rusunawa sebagai tempat tinggal masyarakat Kelurahan Karangroto. Artinya, peluang untuk tinggal di Rusunawa Karangroto antara responden yang menganggap bahwa harga sewa Rusunawa Karangroto merupakan harga sewa yang terjangkau dan tidak terjangkau adalah sama saja. Harga sewa belum bisa menjadi faktor pertimbangan oleh Masyarakat Kelurahan Karangroto untuk tinggal di rusunawa, meskipun jawaban dari sejumlah responden didominasi dengan jawaban harga sewa Rusunawa Karangroto merupakan haga sewa yang dapat dijangkau. Faktor harga sewa adalah pertimbangan relatif, mengingat harga sewa yang ditawarkan oleh pengelola Rusunawa Karangroto merupakan harga sewa yang disubsidi oleh pemerintah. Faktor lain yang dapat menentukan permintaan tinggal masyarakat Kelurahan Karangroto di Rusunawa Karangroto.

Pengaruh Variabel Harga Sewa Terhadap Keputusan Tinggal Masyarakat Karangroto di Rusunawa, variabel harga sewa memiliki nilai koefisien sebesar -0,268 dengan nilai signifikansi
0,845 yang lebih besar dari $\alpha=5 \%$. Variabel harga sewa tidak berpengaruh signifikan terhadap keputusan tinggal masyarakat Karangroto di Rusunawa. Adapun tanda koefisien adalah (-) menunjukkan bahwa adanya penurunan harga sewa akan mempengaruhi kecenderungan masyarakat Karangroto untuk memberikan keputusan tinggal di Rusunawa. Hal tersebut tidak sesuai dengan penelitian yang dilakukan oleh Dahmiri (2010) yang mengungkapkan bahwa harga berpengaruh signifikan terhadap keputusan pembelian rumah. Perbedaan objek yang diteliti dan jenis hunian mempengaruhi dalam hasil penelitian.

Pengaruh Variabel Pendapatan Keluarga Terhadap Keputusan Tinggal Masyarakat Karangroto di Rusunawa, variabel pendapatan keluarga memiliki nilai koefisien sebesar 2,709 dengan nilai signifikansi 0,029 yang lebih kecil dari $\alpha=5 \%$. Variabel pendapatan keluarga berpengaruh signifikan terhadap keputusan tinggal masyarakat Karangroto di Rusunawa. Nilai odds rasio variabel pendapatan keluarga sebesar 0,765 yang berarti probabilitas responden yang berminat menghuni di Rusunawa 0,765 kali lebih besar untuk responden yang mempunyai pendapatan keluarga tinggi dibandingkan responden yang mempunyai pendapatan keluarga rendah. Adapun tanda koefisien $(+)$ menunjukkan bahwa adanya peningkatan pendapatan keluarga akan mempengaruhi probabilitas masyarakat Karangroto untuk memberikan keputusan tinggal di Rusunawa, begitu juga sebaliknya. Hal ini sesuai teori yang dikemukakan oleh Turner (1968) bahwa pada golongan masyarakat yang mengalami peningkatan kesejahteraan mulai memikirkan untuk memiliki rumah sendiri di tempat lain dengan kondisi yang lebih baik.

Pengaruh Variabel Jumlah Anggota Keluarga Terhadap Keputusan Tinggal Masyarakat Karangroto di Rusunawa, variabel jumlah anggota keluarga memiliki nilai koefisien sebesar $-0,832$ dengan nilai signifikansi 0,193 yang lebih besar dari $\alpha=5 \%$. Variabel jumlah anggota keluarga tidak berpengaruh signifikan terhadap keputusan tinggal masyarakat Karangroto di Rusunawa. Adapun tanda 
koefisien (-) menunjukkan bahwa adanya berkurangnya jumlah anggota keluarga akan mempengaruhi kecenderungan masyarakat Karangroto untuk memberikan keputusan tinggal di Rusunawa. Hal tersebut tidak sesuai dengan penelitian yang dilakukan oleh Sumarmi (2011) yang mengemukakan bahwa faktor human input salah satunya adalah keluarga mempengaruhi keputusan dalam memilih suatu hunian. Masyarakat akan secara kondisional menentukan pilihan hunian dengan melihat dari jumlah anggota keluaarga yang akan diikutsertakan untuk menghuni hunian tersebut. Jumlah anggota yang banyak akan memerlukan hunian yang relative besar.

Pengaruh Variabel Kualitas Bangunan Terhadap Keputusan Tinggal Masyarakat Karangroto di Rusunawa, variabel kualitas bangunan memiliki nilai koefisien sebesar 4,380 dengan nilai signifikansi 0,007 yang lebih kecil dari $\alpha=5 \%$. Variabel kualitas bangunan berpengaruh signifikan terhadap keputusan tinggal masyarakat Karangroto di Rusunawa. Nilai odds rasio variabel kualitas bangunan sebesar 79,810 yang berarti probabilitas responden yang berminat menghuni di Rusunawa 79,810 kali lebih besar untuk responden yang mempunyai pandangan kualitas bangunan rusunawa bagus dibandingkan responden yang mempunyai pandangan kualitas bangunan rusunawa tidak bagus. Adapun tanda koefisien (+) menunjukkan bahwa adanya peningkatan kualitas bangunan rusunawa akan mempengaruhi probabilitas masyarakat Karangroto untuk memberikan keputusan tinggal di Rusunawa, begitu juga sebaliknya. Hal ini sesuai teori yang dikemukakan oleh Kotler (2009:49) kualitas adalah seluruh ciri serta sifat suatu produk atau pelayanan yang berpengaruh pada kemampuan untuk memuaskan kebutuhan yang dinyatakan atau yang tersirat. Penelitian lain juga mengungkapkan bahwa aspek kualitas sangat mempengaruhi pemilihan perumahan oleh konsumen (Kalesaran, 2013). Masyarakat akan memlih hunian yang cenderung cocok dengan keinginannya, yaitu hunian dengan kualitas yang lebih bagus.
Pengaruh Variabel Lingkungan Rusunawa Terhadap Keputusan Tinggal Masyarakat Karangroto di Rusunawa, variabel lingkungan rusunawa memiliki nilai koefisien sebesar 3,137 dengan nilai signifikansi 0,008 yang lebih kecil dari $\alpha=5 \%$. Variabel lingkungan rusunawa berpengaruh signifikan terhadap keputusan tinggal masyarakat Karangroto di Rusunawa. Nilai odds rasio variabel lingkungan rusunawa sebesar 23,035 yang berarti probabilitas responden yang berminat menghuni di Rusunawa 23,035 kali lebih besar untuk responden yang mempunyai pandangan lingkungan rusunawa nyaman dibandingkan responden yang mempunyai pandangan lingkungan rusunawa tidak nyaman. Adapun tanda koefisien $(+)$ menunjukkan bahwa adanya peningkatan lingkungan rusunawa akan mempengaruhi probabilitas masyarakat Karangroto untuk memberikan keputusan tinggal di Rusunawa, begitu juga sebaliknya. Hal ini sesuai teori yang dikemukakan oleh Social Aglomeration Theory (1985) dalam Rahma (2010) bahwa orang memilih rumah dengan pertimbangan utama bahwa dia akan nyaman bersama dengan kelompok sosial tertentu dimana kelompok ini bisa terbentuk berdasarkan ras, pendapatan, usia, dan lain sebagainya, yang kemudian timbul segregasi. Penelitian lain juga mengungkapkan bahwa faktor lingkungan sosial mempengaruhi pemilihan hunian social (Kalesaran, 2013). Lingkungan yang serasi dengan kepribadian calon penghuni menentukan seseorang memilih akan hunian yang diinginkan, bahwa lingkungan akan membentuk seseorang nyaman dengan keadaan yang ada di sekitarnya.

Pengaruh Variabel Jarak Tempat Kerja Terhadap Keputusan Tinggal Masyarakat Karangroto di Rusunawa, variabel jarak tempat kerja memiliki nilai koefisien sebesar 0,217 dengan nilai signifikansi 0,010 yang lebih kecil dari $\alpha=5 \%$. Variabel jarak tempat kerja berpengaruh signifikan terhadap keputusan tinggal masyarakat Karangroto di Rusunawa. Nilai odds rasio variabel jarak tempat kerja sebesar 1,242 yang berarti probabilitas responden yang berminat menghuni di Rusunawa 1,242 kali lebih besar untuk responden yang mempunyai jarak 
tempat kerja jauh dibandingkan responden yang mempunyai jarak tempat kerja dekat. Adapun tanda koefisien (+) menunjukkan bahwa adanya pertambahan jarak tempat kerja akan mempengaruhi probabilitas masyarakat Karangroto untuk memberikan keputusan tinggal di Rusunawa, begitu juga sebaliknya. Hasil analisa data pada penelitian ini sesuai dengan teori yang dikemukakan Drabkin (1980) dalam Kalesaran (2013) bahwa ada beberapa faktor yang berpengaruh terhadap pemilihan lokasi perumahan yang secara individu berbeda satu dengan lainnya, salah satunya adalah jarak terhadap pusat kota dan peluang pekerjaan sebagai penunjang kehidupannya. Penelitian ini menemukan bahwa masyarakat akan cenderung memberikan keputusan untuk menghuni rusunawa apabila masyarakat tersebut jauh dari tempat kerjanya. Masyarakat cenderung tidak memilih menghuni rusunawa karena hunian saat ini dekat dengan pekerjaan mereka.

\section{SIMPULAN}

Faktor-faktor yang mempengaruhi keputusan tinggal masyarakat Kelurahan Karangroto di rusunawa secara parsial adalah faktor pendapatan keluarga, faktor kualitas bangunan, faktor lingkungan rusunawa, dan faktor jarak tempat kerja. Masing-masing faktor memunyai nilai signifikansi $<0,05$ sehingga menolak $\mathrm{H} 0$, besar nilai signifikansi masingmasing faktor adalah faktor pendapatan keluarga dengan nilai signifikansi 0,029 , faktor kualitas bangunan dengan nilai signifikansi 0,007 , faktor lingkungan rusunawa dengan nilai signifikansi 0,008 , dan faktor jarak tempat kerja dengan nilai signifikansi $\quad 0,010$. Faktor-faktor yang mempengaruhi keputusan tinggal masyarakat Kelurahan Karangroto di rusunawa secara simultan yaitu faktor harga sewa, faktor model/tipe, faktor kualitas bangunan, faktor lingkungan rusunawa, dan faktor jarak tempat kerja adalah signifikan dengan nilai $\mathrm{p}$-value chi square sebesar sebesar 0,018 dimana kurang dari 0,05 sehingga menerima $\mathrm{H} 1$ dan menolak H0.

Besarnya probabilitas dari masing-masing faktor yang berpengaruh adalah faktor pendapatan keluarga dengan nilai odds ratio sebesar 0,765 yang berarti probabilitas responden yang berminat menghuni di Rusunawa 0,765 kali lebih besar untuk responden yang mempunyai pendapatan keluarga tinggi dibandingkan responden yang mempunyai pendapatan keluarga rendah. Faktor kualitas bangunan dengan nilai odds rasio sebesar 79,810 yang berarti probabilitas responden yang berminat menghuni di Rusunawa 79,810 kali lebih besar untuk responden yang mempunyai pandangan kualitas bangunan rusunawa bagus dibandingkan responden yang mempunyai pandangan kualitas bangunan rusunawa tidak bagus. Faktor lingkungan rusunawa dengan nilai odds rasio sebesar 23,035 yang berarti probabilitas responden yang berminat menghuni di Rusunawa 23,035 kali lebih besar untuk responden yang mempunyai pandangan lingkungan rusunawa nyaman dibandingkan responden yang mempunyai pandangan lingkungan rusunawa tidak nyaman. Faktor jarak tempat kerja dengan nilai odds rasio sebesar 1,242 yang berarti probabilitas responden yang berminat menghuni di Rusunawa 1,242 kali lebih besar untuk responden yang mempunyai jarak tempat kerja jauh dibandingkan responden yang mempunyai jarak tempat kerja dekat.

\section{DAFTAR PUSTAKA}

Budi. S, Mulyo. 2009. "Analisis Permintaan Rumah Sederhana di Kota Semarang". Jurnal Bisnis dan Ekonomi. Volume 16 No. 2. Hal. 126-139. Semarang: Universitas Stikubank Semarang.

Dahmiri. 2010. "Analisis Persepsi Konsumen Terhadap Keputusan Membeli Perumahan Griya Kembar Lestari di Kota Jambi”. Jurnal Manajemen Pemasaran. Volume 2 No. 1. Hal. 36-46. Jambi: Universitas Jambi.

Ghozali, Imam, 2011. Aplikasi Analisis Multivariate Dengan Program IBM SPSS 19. Edisi Kelima. Semarang: Universitas Diponegoro.

Hutomo, ... (2015). Faktor-Faktor Yang Mempengaruhi Keputusan Melakukan Migrasi Ulang-Alik (Studi Kasus Tenaga Kerja Asal Kab. Semarang Ke Kota Semarang Dengan Menggunakan Transportasi BRT). Economics Development Analysis Journal, 4(4). doi:10.15294/edaj.v4i4.8664 
Kalesaran, Ronald C. E., Et al. 2013. "Analisa Faktor-

Faktor yang Mempengaruhi Keputusan

Konsumen Dalam Pemilihan Lokasi

Perumahan di Kota Manado”. Jurnal Ilmiah

Engineering. Vol. 3 No. 3. Hal. 170-184.

Manado: Universitas Sam Ratulangi.

Kelurahan Karangroto (2015), Laporan Monografi Bulanan Keluarahan Karangroto 2015.

Pubosari, Annisa, 2012. "Analisis Faktor-Faktor yang Mempengaruhi Keputusan Bertempat Tinggal di Kota Bekasi Bagi Penduduk Migran”. Jurnal Ekonomi. Vol. 1 No. 1 Tahun 2012. Hal. 1-15. Semarang: Universitas Diponegoro.

Rahma, Intan Sari Zaitun. (2010). "Analisis FaktorFaktor yang Mempengaruhi Permintaan Perumhan Tipe Cluster (Studi Kasus Perumahan Taman Sari) di Kota Semarang". Skripsi. Semarang: Fakultas Ekonomi Universitas Diponegoro.

Sumarmi, Saptaningsih. 2011. "Pengambilan Keputusan Pemilihan Perumahan". Jurnal Akmenika. Hal 1-13. Yogyakarta : Universitas PGRI Yogyakarta.

Supranto, J., 2000, Statistik Teori dan Aplikasi, Erlangga, Jakarta.

Turner, John F.C., 1968. The Squatter Settlement: An Architecture that Works. Architectural Design 38 vol. 8 London, pp. 